BULLETIN Bulletin hispanique

HISPANIQUE Université Michel de Montaigne Bordeaux

113-1 | 2011

Actes de 2 colloques

\title{
Barroco versus Ilustración en el tráfico atlántico de libros
}

Carlos Alberto González Sánchez

\section{(2) OpenEdition}

Journals

Edición electrónica

URL: http://journals.openedition.org/bulletinhispanique/1540

DOI: 10.4000/bulletinhispanique. 1540

ISSN: 1775-3821

Editor

Presses universitaires de Bordeaux

Edición impresa

Fecha de publicación: 1 junio 2011

Paginación: 383-407

ISBN: 978-2-86781-740-3

ISSN: 0007-4640

Referencia electrónica

Carlos Alberto González Sánchez, "Barroco versus Ilustración en el tráfico atlántico de libros », Bulletin hispanique [En línea], 113-1 | 2011, Publicado el 01 junio 2014, consultado el 20 abril 2019. URL : http:// journals.openedition.org/bulletinhispanique/1540 ; DOI : 10.4000/bulletinhispanique.1540 


\title{
Barroco versus Ilustración en el tráfico atlántico de libros
}

\author{
Carlos Alberto González Sánchez \\ Universidad de Sevilla
}

\begin{abstract}
Cet article étudie divers aspects de la circulation des livres entre l'Espagne et l'Amérique latine au XVIII siècle. En premier lieu, il examine les démarches administratives que les intéressés devaient accomplir pour faire parvenir leurs livres de l'autre côté de l'Atlantique, en tenant compte de la censure inquisitoriale et des changements législatifs introduits par la dynastie des Bourbons. Finalement, en ce qui concerne les textes embarqués, l'attention se centre sur la prédominance du Baroque face à l'impact, tardif et progressif, des Lumières.
\end{abstract}

Este artículo estudia diversos aspectos del tráfico de libros entre España e Iberoamérica durante el siglo XVIII. En primer lugar los trámites burocráticos que debian cumplir los interesados en hacer llegar los libros al otro lado del Atlántico, teniendo en cuenta los cambios legislativos que introdujo la dinastía borbónica y la interdicción inquisitorial. Respecto a los textos embarcados, la atención se centra en predominio del Barroco frente al tardio y progresivo impacto de la Ilustración.

This article examines several aspects of the books movements between Spain and Ibero America during the eighteenth century. Primary the bureaucratic procedures that merchants and other people had to carry out when they wanted to send books across the Atlantic, as regard the role of the Bourbon in legislative changes and the Inquisition censorship. Finally, with regard to the shipped books, the Baroque prevalence in front of the slow and progressive impact of the Enlightenment.

Mots-clés : Contrôle de navires - Bourbons - Inquisition - Baroque - Lumières.

Bulletin Hispanique, Tome 113, n 1 - juin 2011 - p. 383 à 407. 
Entre les différentes causes qui ont concouru à nous tirer de la barbarie, il ne faut pas oublier l'invention de l'art typographique.

Denis Diderot

\section{Registrar Y VIGILAR}

La intervención de la Inquisición en el control del tráfico de libros de la Carrera de Indias hizo más complejos, lentos y dificultosos todavía los trámites burocráticos exigidos a los cargadores de productos tipográficos, ya fueran mercaderes o particulares. Además de entregar en la Contratación el registro de las cosas que querían embarcar, tendrían que presentar en la sede del Santo Oficio una relación descriptiva del material gráfico en cuestión. Allí dichas listas eran remitidas a los calificadores previstos para su inspección, quienes, en caso de no encontrar inconvenientes, otorgaban la autorización de salida pertinente. He aquí, junto a la orden de Carlos V de 1550, la razón principal por la que encontramos en la documentación al uso del Archivo de Indias (los registros de ida de naos), con cierta regularidad a partir de 1583, listas detalladas de libros; sin embargo, dejan de ser habituales hacia 1660, o sea, a raíz de la supresión de la avería, el único tributo obligatorio para los impresos y con el que se sufragaba la defensa militar de las flotas. Desde entonces no fue obligatoria la anotación unitaria en los registros de la mercadería con destino al Nuevo Mundo; así, los libros vuelven a registrarse por lotes, siempre con el permiso escrito de los inquisidores ${ }^{1}$.

Como brillantemente puso de relieve P. Rueda, ya hacia 1620, por motivos fiscales, se detecta la práctica de dejar sin aclarar el contenido de cajas, baúles y fardos, pues los cambios acaecidos en la hacienda de la navegación atlántica ocasionaron que la declaración de los géneros dejara de ser ad valorem. De este modo, las memorias de libros se convierten en un requisito exclusivo del Santo Oficio y distinto a los de la Contratación. Estos cambios hicieron que las listas de libros no tuvieran que ir cosidas en los registros que exigía

1. Los mejores estudios sobre esta cuestión son los de Pedro Rueda Ramírez, «La vigilancia inquisitorial del libro con destino a América en el siglo XVII», en Grafias del imaginario. Representaciones culturales en España y América (siglos XVI-XVIII), C. A. González y E. Vila comps. México, Fondo de Cultura Económica, 2003, pp. 140-156; y su gran obra Negocio e intercambio cultural: el comercio de libros con América en la Carrera de Indias (siglo XVII), Sevilla, Deputación de Sevilla, CSIC, Universidad de Sevilla, 2005. Alguna información he aportado en mi libro Los mundos del libro. Medios de difusión de la cultura occidental en las Indias de los siglos XVI y XVII, Sevilla, Universidad de Sevilla, 1999. 
la Casa, por ser dos certificados independientes y el resultado de gestiones administrativas diferentes. No obstante, las modificaciones aludidas no conllevan la ausencia de las mismas en los documentos de fechas posteriores; sirva de testigo este ensayo en el que reflexiono sobre libros europeos enviados a las Indias durante el siglo XVIII. Mas resulta difícil abarcar en unas cuantas páginas los múltiples recovecos visibles en las fuentes manejadas; a ello se debe que, para dar una idea de sus ricas posibilidades, me limite a ofrecer unos trazos sobre aspectos de especial relieve e interés.

Con semejante propósito he tomado como eje fundamental, aparte de otros, un centenar de memorias de libros prestos a salir rumbo a América desde el puerto de Cádiz (cabecera del tráfico ultramarino desde 1680), entre 1700 y 1750, de las flotas de Nueva Espańa y Tierra Firme, registradas por un representativo grupo del comercio tipográfico sevillano, en el que predominan renombradas casas como las de Pedro Santiago, Diego López de Haro, Lucas Martín de Hermosilla, Antonio Vargas y el flamenco Nicolás Vercolme. Tampoco faltan entre los cargadores órdenes religiosas (con predominio de dominicos, jesuitas y franciscanos) y, en menor medida, funcionarios, instituciones varias y muchos particulares con intenciones privadas y mercantiles. Los puertos de destino, a su vez, son Veracruz y Nombre de Dios, localidades desde donde la mercancía libraria sería distribuida a lo largo y ancho de las Indias, a través de libreros, mercaderes, clérigos, funcionarios, profesionales, órdenes religiosas, universidades, centros de estudio diversos y una clientela variopinta ${ }^{2}$.

La cronología de los documentos corresponde a un tiempo en el que, dentro del circuito legal del comercio atlántico y según García-Baquero, se exportaron un total de 13.601 cajones de libros (1.635 toneladas), con una media de 10 a 20 impresos por cajón ${ }^{3}$. Una cantidad, a todas luces, incapaz de abastecer una demanda americana en expansión gracias al progresivo aumento de los factores que la determinan: el desarrollo urbano, una alfabetización cada vez más necesaria, las infraestructuras educativas, el equipamiento cultural, el nivel intelectual de la población, los mercados tipográficos o las necesidades eclesiásticas y gubernamentales. Esta insuficiencia de los suministros peninsulares -donde nunca hubo una

2. Las listas, examinadas por la Inquisición en Sevilla, se encuentran en el legajo 674 de la sección de Contratación del Archivo General de Indias.

3. Antonio García-Baquero, Cádiz y el Atlántico. 1717-1778, 2 vols. Cádiz, Diputación de Cádiz, 1988. Del mismo autor El comercio colonial en la época del absolutismo ilustrado. Problemas y debates, Granada, Universidad de Granada, 2003. Son dos estudios de suma utilidad para la Carrera de Indias durante el siglo XVIII, por ello los voy a tomar como referentes prioritarios. 
industria editorial a la altura de las circunstancias y capaz de competir con los principales centros europeos (Francia, Flandes, Alemania e Italia)vendrían a compensarlas otras alternativas entonces muy corrientes $y$, en multitud de ocasiones, al margen de la legalidad: las exiguas tiradas de los tórculos indianos, las copias manuscritas o las ediciones contrahechas. Pero el remedio más común fue el contrabando, el gran problema, en connivencia con la corrupción administrativa del sistema, al que, sin aportar nunca soluciones del todo eficaces, hubieron de doblegarse las autoridades de las dos orillas del Océano. Una opción, en cualquier caso, que restaba toda posible solvencia no sólo a los métodos de control ideológico ideados sino al monopolio de la Carrera de Indias en general.

En efecto, sin la complicidad de los operarios de la Contratación, aduanas y puertos no se hubiera dado un fraude tan generalizado. A ellos se suman los inquisidores, quienes, además de carecer a menudo de la preparación intelectual adecuada y estar sobrados de desidia y escasa motivación, normalmente se limitaban a evaluar visualmente las listas de los cargadores, sin verificar en el lugar oportuno si el contenido de las mismas coincidía realmente con los libros por embarcar. Incluso aprovechaban las inspecciones que debían realizar en los navíos para, a fuerza de hacer la vista gorda, comprar mercancías a bajo precio, recibir regalos de los responsables del barco, ser agasajados con banquetes e, incluso, prebendas sexuales. Otra traba radica en los continuos inconveniente que los oficiales reales ponían a los comisarios del Santo Oficio durante las visitas de las naos llegadas a Indias, unos altercados jurisdiccionales endémicos que continuamente la Corona resolvía a favor de la primacía de los comisarios inquisitoriales en dichos protocolos de control; como en el Decreto de 31 de enero de 1713, en el que se pide al Consejo de Indias exhortar a mandatarios y justicias de América no impidiesen «el libre ejercicio y jurisdicción del Santo Tribunal y que pudiesen visitar sus ministros todos los navíos a fin de evitar la introducción de los que fuesen contra el candor de la fe» ${ }^{4}$.

El regsitro, la salvaguarda del entramado fiscalizador activado, definitivamente abría la puerta a todo tipo de fraudes, pues terminó convirtiéndose en una obligación administrativa, banalizada por la costumbre, que confiaba casi exclusivamente en las declaraciones escritas, en general ilegibles, de los mercaderes. Ya Veitia Linaje, a finales del siglo XVII, lo calificó como diligencia infructuosa y materia intratable; respecto a los de libros sentencia que «con escribir aquellos de que las partes diessen relación,

4. José Ayala, Manuel, Diccionario de Gobierno y Legislación de Indias, Madrid, Cultura Hispánica, 1990, tomo VIII, p. 290. 
no se aplicava el remedio, pues no pondrían en ella los prohibidos aunque los llevasen" ${ }^{5}$. Un caso curioso sucedía en el Perú de finales del siglo XVIII, donde el Virrey Croix, en un despacho del 28 de febrero de 1787, informa que la inexistencia de un lugar adecuado en el que, de acuerdo con las leyes, almacenar los libros en espera de inspección, facilitaba que sus propietarios se los llevaran de los locales provisionales en donde se guardaban, facilitando de esta manera la burla de los controles pertinentes ${ }^{6}$. Todas estas circunstancias hicieron muy factibles estratagemas como las portadas falsas, ocultamientos y otras tretas delictivas. Tampoco debemos dejar de lado la relajación de la política restrictiva aduanera que, con frecuencia, conllevaban los tratados de paz que hubo de firmar la Corona española, que, en caso de ser desfavorables, dejaban inermes las fronteras hispanas frente a los mercaderes de sus naciones rivales.

Portugal contemplaba un sistema de control parecido, aunque mucho más centralizado en Lisboa, que exigía a todo aquel que quisiese enviar libros a Brasil solicitar a la Inquisición una licencia para poder embarcar cualquier material impreso. La llamada Real Mesa Censoria (comienza a actuar en 1769) fue la encargada de conceder las licencias en cuestión, previa presentación por los interesados de una relación detallada de las obras. En la Mesa sus censores examinaban las listas y, en caso de dudas, ex profeso aquellos libros que levantaran desconfianza; concedida la autorización el solicitante pagaba una pequeña tasa. Según el estudio realizado por M. Abreu, entre 1769 y 1826 (independencia de Brasil) se registraron unas 700 solicitudes para Río de Janeiro, 700 para Bahía, 700 para Pernambuco, 350 para Maranhâo y 200 para Pará, que contabilizan un total de 18.903 títulos, la mayoría religiosos o de carácter profesional, seguidos de los literarios. Del mismo modo al otro lado del Atlántico se instituyó la Mesa de Desembargo do Paço, con la misión de vigilar la llegada de libros a tierras brasileñas y, en última instancia, evitar la entrada de textos sin licencia ${ }^{7}$.

5. José de Veitia Linaje, Norte de la Contratación de las Indias Occidentales, edic. de F. de Solano, Madrid, Instituto de Estudios Fiscales, 1981, p. 203.

6. Guillermo Lohmann Villena, «Libros, libreros y bibliotecas en la época virreinal», Fénix, Revista de la Biblioteca Nacional, no 21, 2000, p. 5 y ss.

7. En los archivos de Lisboa se custodia el Catálogo para examen de los libros para que salgan del Reino con destino a Brasil, que contiene miles de solicitudes de autorización para mandar libros a Brasil. Véase Marcia Abreu, Os caminhos dos livros, Campinas, Mercado de Letras, 2003, pp. 139 y ss. También Luiz C Villalta, «O que se fala e o que se lê: lingua, instruçao e leitura», en Cotidiano e vida privada na América portuguesa, L. de Mello Souza dir., Sâo Paulo, Companhia Das Letras, 1997, pp. 331-386. 


\section{EL ESPÍRITU DE LAS LEYES}

El siglo XVIII hispánico llega de la mano de los Borbones, una nueva dinastía de origen francés que de acuerdo a la tradición política gala pondrá en marcha un programa de reformas de largo alcance, con la intención, en primer lugar, de poner orden en el caos heredado de los Habsburgo y, a la postre, lograr un gobierno más centralizado y autoritario. Mas uno de los objetivos prioritarios fue la recuperación del imperio atlántico español, postrado tras la decadencia del siglo XVII. Estos nuevos planteamientos políticos trajeron consigo una serie de cambios que, pese a no incidir directamente en el tráfico ultramarino de libros -en líneas generales sujeto a la legislación de los Austrias-, tendrán una relativa repercusión en las relaciones económicas entre España y América. En esta línea, y como colofón de un proceso iniciado en 1680, se culmina el traslado de la capital del monopolio de la Carrera de Indias a Cádiz con el establecimiento allí, en 1717, de la Casa de la Contratación y el Consulado de comerciantes. Pese a ello, el comercio sevillano seguiría teniendo un importante peso específico, por reservarse como derecho privativo un tercio del tonelaje útil de las flotas. De ahí que los libreros hispalenses (activos intermediarios de las grandes firmas nacionales y extranjeras, especialmente respecto al libro culto) no fueran desbancados por los gaditanos hasta la segunda mitad de la centuria. La diferente localización de la sede de la empresa colonial americana sólo conllevó una nueva plataforma de los negocios ultramarinos, pero no el cambio de residencia de los cargadores de la Carrera de Indias.

Mayor impacto tuvieron las novedades impuestas en el tráfico y la navegación, consistentes en la generalización, a partir de 1739, del sistema de navíos sueltos (conocidos también como registros) en cualquier fecha del año y al margen de las flotas. La Carrera, de este modo, ganó en flexibilidad, rapidez y regularidad, con una repercusión muy positiva en el abastecimiento de unas Indias en exceso supeditadas a los dos suministros peninsulares anuales reglamentarios. En la misma directriz están, desde 1728, las compañías privilegiadas de comercio y navegación, entidades fruto de la iniciativa privaba con el amparo estatal que, agraciadas por la Corona con suculentas exenciones y franquicias (fiscales, fabriles, comerciales, dinerarias, etc.), posibilitaron la progresiva quiebra del monopolio de la Baja Andalucía, la participación de las burguesías periféricas españolas en el comercio colonial (Aragón, Cataluña, Guipúzcoa, Extremadura) y, en general, un mejor desarrollo económico regional. Tampoco puedo dejar de mencionar, dada su incidencia en el entorno tipográfico español y su endémica dependencia del exterior, las naturalizaciones y licencias concedidas a mercaderes extranjeros, 
quienes hasta entonces, y a no ser que acudieran a testaferros, habían visto muy mermadas sus posibilidades de intervenir directamente en los negocios indianos. Las primeras abrieron la puerta a una especie de "nacionalización", con sus derechos inherentes y previa solicitud, a los comerciantes foráneos con diez años o más de domicilio estable en la Andalucía atlántica; mientras que las segundas contemplaban permisos especiales para aquellos que habían prestado determinados servicios (normalmente pecuniarios) a la Corona.

En este contexto, imprescindible resulta atender a la legislación sobre el libro y América promulgada durante el Setecientos. De entrada, la normativa decretada por los Borbones en líneas generales no difiere mucho de la de los Austrias, aunque sí es menos voluminosa e insistente. Todos los monarcas dictaron leyes al respecto y, como en tiempos pasados, con la finalidad última de preservar la ortodoxia religiosa y la firmeza ideológica de sus dominios hispánicos, para ponerlos a salvo de conductas e ideas subversivas del exterior. La integridad del Imperio en cualquiera de sus flancos en gran medida dependía de la política internacional regia, una estrategia cuya meta no era otra que volver a hacer de España una potencia mundial de primera línea, objetivo explícito y preferente durante el gobierno reformista de Carlos III. Repasemos los hitos legislativos más llamativos del siglo.

En 1709 Felipe V, en medio de la Guerra de Sucesión, de nuevo y como en tiempos pasados, decreta la prohibición de introducir en Indias Biblias extranjeras, sospechosas o editadas en países protestantes, una medida frente al continuo avistamiento de impresos de este cariz en tierras americanas. En concreto, a todas las autoridades de América, civiles y religiosas, se les exige una enfática precaución en la detección de unas Sagradas Escrituras en lengua indígena publicada en Londres, de la que se tiene noticia gracias a un Breve papal que el Inquisidor General había entregado al Rey ${ }^{8}$. Un impreso demasiado pernicioso, corrompido y, dice la Cédula, «con adiciones erroneas y con deprabada interpretación de los hereges, solapando sus errores con ánimo de que se divulgase en Yndias para apartar a los sencillos

8. No he encontrado ninguna referencia de esta edición bíblica de Londres. Sólo me consta una traducción y comentario de los Evangelios en quechua realizada por Esteban Sancho de Melgar, catedrático de teología y quechua de la Universidad de San Marcos de Lima, pero que nunca llegó a publicarse y sólo circuló manuscrita. Tomo la información de J. Specker, "Aprecio y utilización de las Sagradas Escrituras en las Misiones Hispanoamericanas», San Marcos, no 9, 1968. Una remota posibilidad es que se trate de la Biblia, en lengua india, que editó John Eliot (1661-1663) en Nueva Inglaterra; vése The Colonial Book in the Atlantic World, H. Amory y D. Hall eds. Cambridge, Cambridge University Press, 2000, p. 18. 
yndios de la religión, e inducirlos a que abrazasen sus sectas» ${ }^{9}$. De nuevo, cual fue la consideración oficial desde el principio de la colonización, se acude a la ingenuidad de los naturales como una vía oportuna para la fácil manipulación de sus conciencias y, en última instancia, para la penetración de la herejía en el Nuevo Continente. Téngase en cuenta que la ley nunca se anticipa a la realidad y, en todo momento, pretende dar soluciones a situaciones o prácticas vigentes consideradas anómalas o contrarias a los fines del poder; por ello, cuando es reiterativa, pone de manifiesto, y he aquí lo más interesante, el arraigo de determinadas conductas ilícitas en la realidad cotidiana, y, a la par, la ineficacia de sus antídotos legislativos.

Dos años más tarde, el 20 de julio de 1711, y conforme a la proliferación de libelos y panfletos contrarios a la causa borbónica, y a favor de la austracista, en la contienda sucesoria, una real cédula exhorta a los prelados de las colonias a atajar la difusión de tan ignominiosos papeles, así como al castigo de quienes se sirvieren de estas tretas, con especial atención a los eclesiásticos. El motivo aducido redunda en que

introduciendo la contagiosa semilla de la desafección, y disidencia, esparciéndola en ellos, gacetas y otros papeles, e inquietar la lealtad, y fidelidad de aquellos vasallos, y debiendo precaber cuanto pudiese mirar a su quietud, alivio y consuelo, contribuyendo su paternal amor a que fuesen tanto más atendidos, quanto más distantes ${ }^{10}$.

El 23 de octubre de 1722, una vez más se reafirma la exención de tributos para los libros prestos a cruzar el Océano, una franquicia de la que los mercaderes venían beneficiándose desde principios del siglo XVI y que, definitivamente, refrendaría Carlos V en una real cédula de 1548. Si bien, este decreto de Felipe $V$ responde a la entrada en vigor del nuevo reglamento fiscal de la Carrera de Indias, en el que el viejo almojarifazgo fue sustituido por el derecho de palmeo como el impuesto obligatorio de cualquier negocio mercantil transatlántico, basado no en el valor de la mercancía sino en el espacio útil -medido en palmos cúbicos- que ésta ocupaba en los buques y sobre el que se cobraba un canon fijo. No obstante, el Real Proyecto de Galeones y Flotas de 1720 gravó los impresos espańoles con 5 pesos por cada cajón de media carga, y 20 los extranjeros. En Cartagena y Portobelo, además, contribuían el 2 por ciento los nacionales y el 4 los foráneos.

9. Manuel José de Ayala, Diccionario de Gobierno, op. cit., p. 289.

10. Fermín de los Reyes Gómez, El libro en España y América. Legislación y censura (siglos XV-XVIII), 2 vols., Madrid, Arco/Libros, 1999, p. 902. El volumen 2 de esta obra recoge toda la legislación relativa a libros e impresos que dictó la Corona española durante la Edad Moderna. En él he seleccionado la del siglo XVIII. 
Mas las reclamaciones de comerciantes de Madrid y Sevilla, esgrimiendo fórmulas y leyes anteriores, lograron en 1721 la exclusión, excepto la avería, de cualquier carga fiscal; sin embargo, hasta 1780 no quedarían exentos los libros espańoles que embarcasen pasajeros para uso particular, mientras que los registrados como géneros mercantiles pagarían un 3 por ciento de su valor. Los del exterior, en cambio, tributarían los derechos de salida y entrada vigentes. Al igual, el 8 de mayo de 1778, a petición del Consulado gaditano, se insta al Comisario de la Inquisición de Sevilla destacado en el puerto de Cádiz, deje de cobrar los 4 reales de plata por las licencias de cada cajón embarcado; una atribución, al margen de la confirmación regia, sancionada por la costumbre.

En ámbitos intelectuales mayor repercusión y resonancia tuvo un decreto del 11 de abril de 1729 en el que, conforme a la licencia concedida al impresor madrileño Francisco Martínez Abad para tirar y distribuir determinados textos en América, se rehabilitan unas obras de polémico renombre tiempo atrás; nada menos que la Historia general de las Indias de López de Gómara y la Historia del Perú de Diego Fernández de Palencia. La nueva coyuntura política distaba mucho de la que en el siglo XVI propició el veto de títulos como los mencionados, publicados en unas fechas en las que no había concluido la conquista del Nuevo Mundo. La colonización y la evangelización, pues, eran empresas emergentes y en el punto de mira del acoso, desde todos los frentes (con especial protagonismo del propagandístico), de unos rivales europeos siempre deseosos de argumentos ideológicos antiespañoles. Llegamos así a 1741, cuando, tras años de certificadas evidencias de la circulación sin trabas de impresos de temática americana sin las licencias pertinentes de los Consejos de Castilla e Indias, el viejo Felipe V, en el Buen Retiro el 28 de octubre, y luego en 1742 y 1743 , de nuevo reitera la obligación que recae sobre todo escrito relativo al Nuevo Continente de ser examinado antes de obtener la licencia de edición correspondiente. La ley se hace eco de «que de algún tiempo a esta parte se han dado a luz varios libros de diferentes historias y materias pertenecientes a Indias, impresos con las licencias correspondientes y ordinarias de mi Consejo de Castilla, pero sin la de el de Indias...» ${ }^{11}$.

Este asunto de las licencias se había convertido en una falla impertérrita de la política regia de control cultural, que desde el siglo XVI venía sin encontrarle un remedio efectivo. Un obstáculo con el que continuamente tropezaba estaba en las infracciones que impresores (siempre acuciados por deudas) y libreros cometían, porque no podían permitirse el lujo de aguantar

11. Reyes Gómez, op. cit., p. 931. 
las lentísimas y tediosas exigencias burocráticas editoriales de la Corona. Su resolución, además, sólo era posible en la Corte, pese a las reivindicaciones que, en siglos anteriores, los afectados elevaron para descentralizarlas y, en última instancia, hacer más ágil la producción de la imprenta y su posterior distribución comercial. Por ello, y con mayor frecuencia que la detectada en la documentación al uso, los implicados en la tipografía, para evitar pérdidas de beneficios o, simplemente, la amortización de sus inversiones, solían prescindir de dichos requisitos legales. Tales estratagemas, entre otros muchos durante el Setecientos, es denunciada por Manuel José de Ayala, eminente jurista y anotador de las leyes de Indias que, a mediados del siglo XVIII, las ve especialmente perjudiciales y de urgente erradicación, sobre todo cuando incumben a libros extranjeros y al margen de todo posible control.

A Felipe V le sucede Fernando VI, quien en su breve reinado, en primer lugar, vuelve a incidir en la necesidad de impedir la estampa, sin una calificación preliminar, de los pliegos con

sátiras y cláusulas denigrativas del honor, y estimación de las personas de todas clases y estados, y aun de los que constituidos en dignidades y en empleos de distinción...queriendo desterrar este abuso tan pernicioso, y contrario a la caridad cristiana, a la Sociedad civil y a la decencia ${ }^{12}$.

Una muestra de la afición de aquella época a la sátira, un género que la imprenta y el pliego (el formato tipográfico más barato y fácil de distribuir) contribuyeron a vulgarizar. No era raro que las calles de la noche a la mańana aparecieran inundadas de papeles con caricaturas de personajes, denuncias de medidas gubernamentales impopulares $\mathrm{u}$ otros asuntos de diversa índole ${ }^{13}$. Algo parecido debió suceder en Manila hacia 1753, fecha en la que el monarca apercibe a sus mandatarios locales para que corten de raíz tan denostado método propagandístico. No hubo más en esta etapa.

Llegamos así a Carlos III, un rey y un reinado de hondo calado historiográfico y el periodo álgido de un reformismo muy aplaudido en la época y, a veces, en la actualidad, cuyos artífices y protagonistas hemos de buscarlos antes entre ministros y hombres de estado del tiempo (Aranda, Campomanes, Floridablanca, Olavide) que en la capacidad personal e inteligencia política del monarca, a todas luces mediocres, aunque superior

12. Reyes Gómez, op. cit., p. 943.

13. Unas interesantes notas de estos escritos ofrece Antonio Castillo Gómez, Entre la pluma y la pared, Madrid, Akal, 2006. 
a la de sus antecesores. Respecto a nuestro objeto de interés he de decir que su labor legislativa se centró en la censura o prohibición de determinadas obras, una actitud propia de un déspota ilustrado temeroso de las, a su juicio, desordenadas apetencias y afanes innovadores, sociales y culturales, de las Luces europeas ${ }^{14}$. Presenciamos entonces una España Ilustrada reducida a una minoría de intelectuales (Mayans, Jovellanos, Olavide, Campomanes, Macanaz) y, a diferencia de la francesa, algo menos elitista, con unos postulados fundamentados en unas reformas de corto alcance que, salvo excepciones, cual fue la voluntad real, de sus ministros y gentes de letras relevantes, nunca sobrepasaron la letra de los decretos ni la ortodoxia, la fidelidad a la autoridad, el sistema socioeconómico o el orden político establecidos. Tal vez a ello responda una, aparentemente, contradictoria simbiosis entre el deseo de novedades y el respeto a la tradición, entre la glorificación de la inteligencia y la perversa e interesada justificación de la Inquisición.

En esta tesitura una Orden de 1761 (el 27 de febrero), a instancias del prior de San Lorenzo del Escorial, previene al Presidente de la Contratación de Cádiz para que pusiera todos los medios posibles con el fin de impedir el embarque de libros del Nuevo Rezado sin el pertinente reconocimiento y licencia del apoderado que, a tal efecto, tenían los Jerónimos en aquel puerto, cuya misión no era otra que preservar los privilegios del mencionado Monasterio frente a una competencia alternativa, la extranjera en especial. La vulneración de estas prerrogativas de los religiosos escurialenses, en la que subyacen unos suculentos factores económicos, seguía sin encontrar una solución eficaz desde que les fueran concedidas en el siglo XVI. A estas alturas observamos que todas las leyes en repaso reproducen otras dictadas por los monarcas de los dos siglos anteriores, es decir, recaen sobre una serie de anomalías enquistadas en el tráfico atlántico de libros que en modo alguno encuentran la enmienda oportuna en el transcurso del tiempo ni en la experiencia del sistema. Las razones, cual estamos viendo, giran en torno a los límites, propios de la época, de la burocracia administrativa, la corrupción y a un variopinto sinfín de intereses particulares.

También en 1761, un decreto emitido en Madrid advierte, encarecidamente, que la quema, en la lonja de la cárcel de la Corte (el 5 de abril de 1759) de dos libritos de Juan de Palafox con las cartas que escribió al jesuita Andrés de Rada, se hizo sólo por carecer ambos de las licencias necesarias.

14. Véase al respecto Antonio Domínguez Ortiz, La España ilustrada de Carlos III, Madrid, Alianza, 1988; y Jean Sarrailh, La España ilustrada de la segunda mitad del siglo XVIII, Madrid, Fondo de Cultura Económica, 1979. 
El documento, a la par, reafirma la ortodoxia y respetabilidad de la doctrina y memoria del Venerable Obispo, para así quitar en lo futuro todo pretexto, con que la malicia, o ignorancia pudiesse denigrar su fama. Con todo, esta manera de proceder hacía alarde de la equidad del poder y la justicia frente a infractores de cualquier clase y condición. Por los demás habría que mencionar el nombramiento de censores, a las órdenes de la Corona, en las universidades americanas y la que creo fue una medida legal de las más decisivas, aunque, por demasiado tardía, de consecuencias muy limitadas. Me refiero a la supresión, el 14 de noviembre de 1762, de la tasa de los libros o precio fijo de cada texto que, en función de sus pliegos, acordaba el Consejo al tiempo de concederles licencia de impresión y privilegios de venta. Aquel sistema de censura previa, acorde a determinados fines gubernamentales, durante más de dos siglos dejó a la manufactura tipográfica fuera de los entresijos gananciales de la oferta y la demanda, ocasionando un grave perjuicio, además de otros ya tratados, a sus agentes económico, indefensos frente a la agresiva rivalidad extranjera.

El resto de la labor normativa de Carlos III muestra, como venía sucediendo desde los Reyes Católicos, la endémica suspicacia estatal hacia los libros importados (1763); las órdenes, así, versan sobre la confiscación y prohibición de textos nocivos detectados circulando libremente a lo largo y ancho de las Indias. Llamativo es una cédula del 8 de octubre de 1779 apremiando a los virreyes de Buenos Aires y Lima al secuestro del libro francés Apocalipse de Chiokoyhikoy Chef des Yroquois Sauvages de Nord de l'Amerique, y uno escocés sobre el descubrimiento de América de Guillermo Robertson, rector de la Universidad de Edimburgo. A continuación, el 21 de octubre de 1782, el Rey se dirige al virrey de Buenos Aires ordenándole la retirada de la Historia del Perú del Inca Garcilaso, un título estimado, conforme a las directrices del siglo XVI, pernicioso para la correcta occidentalización de los indios por fijar sus creencias y costumbres ancestrales, de ahí que se le responsabilice de haber «aprendido esos Naturales muchas cosas perjudiciales y malas costumbres» ${ }^{15}$.

En 1787 tocará el turno al virrey de México, a quien se urge la confiscación y quema en Nueva España de las obras de Marmontel, Montesquieu, Linguet, Raynal, Maquiavelo y la Enciclopedia, autores, y el monumento editorial (todos en el Índice inquisitorial), representativos de la Ilustración francesa, con una acusada intención crítica hacia el régimen monárquico-señorial y la sociedad estamental. Idéntica actitud prevalece durante el reinado de Carlos IV, el epígono de un siglo en el que a cualquier precio había que impedir

15. Reyes Gómez, op. cit., p. 1115. 
la entrada y eliminar en los dominios hispánicos las ideas, y sus soportes propagandísticos, ilustradas, las de la independencia de las Trece Colonias de Norteamérica y, ante todo, las revolucionarias francesas, o semejantes, y cualquiera que promoviera la sedición frente a la autoridad; como expresa una cédula del 10 de septiembre de 1791: «cualesquiera cartas o papeles sediciosos y contrarios a la fidelidad, y a la tranquilidad pública» ${ }^{16}$. La Inquisición, por su parte, se encargaría de anular escrito alguno que atentara contra la doctrina cristiana, las instituciones reales y las autoridades civiles y eclesiásticas, así como las que alentaran actitudes inmorales o desviadas de la fe y las buenas costumbres.

\section{MÁS DE LO MISMO}

La premura de espacio me obliga a hacer un análisis selectivo de tan suculenta muestra de libros y géneros temáticos como la hallada en las listas consultadas. De ahí que haya decidido centrarme en la literatura, tanto laica como religiosa, porque ninguna de las taxonomías discursivas avistadas compite en volumen con ella. Ya constaté que se trata de un segmento gráfico propio de aficiones y metas socioculturales comunes, de alto consumo y popularidad, no sólo específico de un sector socioprofesional definido de los habituales en los inventarios de bienes post mortem, fuente cuyo contenido, sin desmerecer en interés ni utilidad, suele presentar una estrecha vinculación con el estatus laboral de sus titulares. Atenderé, pues, a una producción masiva de la imprenta de la época que reportó importantes beneficios a sus agentes económicos (productores, editores y distribuidores). No en balde uno de los mayores atractivos de los documentos utilizados reside en la naturaleza de los trámites que los gestaron, en general alusivos a los prolegómenos de operaciones comerciales proyectada tras el sondeo de la demanda de la sociedad colonial. Responden, por tanto, a la aritmética de las ganancias auspiciadas a sabiendas de lo que va a ser vendido, aunque la oferta por sí sola también estimula la demanda, circunstancia que en aquel mercado debe tenerse muy en cuenta. En fin, toda una inmejorable casuística en torno a los libros y las personas involucradas en la difusión de la cultura occidental en la América hispana.

El total de los libros contabilizados alcanza una cantidad cercana a los 5.000 volúmenes, de muy diversas materias: teología, derecho, oratoria sagrada, liturgia, gramática, medicina, ciencia y técnica, historia, cartillas

16. Ibid, p. 1149. 
escolares, pliegos, espiritualidad, clásicos greco-latinos y creación literaria; en fin, las taxonomías corrientes en la documentación bibliográfica de entonces. Los asuntos religiosos, y así lo esperaba, representan el 65 por ciento del total; pero, en general, y obviando la ingente cantidad de cartillas y pliegos, la mayor cuantía absoluta corresponde a la literatura, laica (20\%) y religiosa ( $25 \%$ ), acaparadora del 45 por ciento de la muestra. Aparte de las novedades que, dentro de un esquema ideológico y temático homogéneo y aceptado, se van incorporando conforme avanza la cronología de referencia, lo encontrado puede reproducir una maqueta precisa de lo habitual durante el siglo XVII. No por casualidad despunta la escolástica, la historia, la ascética, el neoestoicismo, una ciencia tradicional y la prosa didáctico-moralizante; en pocas palabras, el entorno ideal de la ortodoxia católica y los presupuestos de la Contrarreforma que pretendían contrarrestar el credo protestante o, siquiera, textos portadores de la oración de quietud, aventuras y ficciones, supersticiones, maquiavelismo o copernicanismo.

Contemplamos, pues, la perpetuación del Barroco, una cultura que en el mundo hispánico se prolonga al menos hasta la primera mitad del XVIII, su fase tardía en la que se observan algunas de sus más excelsas manifestaciones, eso sí, desmesuradas, extremadas e hiperbólicas; no obstante Maravall opina que el sentido de la época ya es distinto. Ahora eclosiona una producción cultural mediocre, con un claro sesgo pedagógico, destinada a las masas. Vayamos por partes.

La literatura religiosa es un piélago difícil de desentrañar, con una diversidad temática plena de matices: oratoria, doctrina, hagiografía, espiritualidad; pero, dada su alta producción y popularidad, me voy a centrar en esta última. El consumo generalizado que la caracteriza no sólo la convierte en un género propio de sectores sociales concretos, los de mejor nivel económico y educativo, sino de la comunidad en su conjunto, cual fue la pretensión de la jerarquía eclesiástica en aras de la difusión de una determinada vivencia religiosa entre los fieles, garante de una meta salvífica insoslayable ${ }^{17}$. Creada con un notorio afán divulgativo, sirviéndose de la imprenta y de una promoción interesada desde arriba, acaparó una tipología tipográfica barata y de fácil manipulación: en rama y tamaño reducido (en cuarto y en octavo). Al igual, la técnica discursiva de sus autores se beneficia del romance, la vulgarización de proposiciones abstractas y complejas, el

17. Un trabajo de obligada consulta es el de L. Carlos Álvarez Santaló, «Adoctrinamiento y devoción en las bibliotecas sevillanas del siglo XVIII", en La religiosidad popular II. Vida y muerte: la imaginación religiosa, Barcelona, Anthropos, 1989, pp. 21-41. Por supuesto, Melquiades Andrés, Historia de la mística de la edad de oro en España y América, Madrid, Biblioteca de Autores Cristianos, 1994. 
énfasis en el consuelo vital y anímico y de sus supuestos efectos miríficos. No menos decisiva es su convergencia con la prosa de ficción, desplegada a través de un abismo de maravillas y portentos, de métodos de captación extrarracionales conforme a la norma de adoctrinar y disciplinar deleitando y divirtiendo que popularizó el Barroco en su vertiente más masiva ${ }^{18}$. En definitiva, auténticos espejos de perfección que pretendían alejar a los hombres de una realidad injusta y cruel para conducirlos, mediante unas pautas de conducta específicas, a otra realidad virtual sin angustias y dispensadora de justicia, bondades, consolación, purificación y esperanzas.

El núcleo esencial, claro está, lo protagoniza la ascética, con textos que recrean las virtudes ideales del buen cristiano y las técnicas de la oración interior más gratificantes. Esta última gira en torno a la meditación realista o imaginativa (de la pasión de Cristo, los dolores de María o las postrimerías del Hombre), una modalidad, cerrada acorde a unos cauces y modelos definidos, al margen de la quietud mística y sustentada en los ritos y ceremonias del catolicismo contrarreformista ${ }^{19}$. En esencia consiste en la divulgación de doctrinas y teologías elevadas, pero con una clara intencionalidad educativa, directa y fácil de entender. Entre los títulos hallados vuelven a aparecer los célebres escritores del Quinientos que ya presagiaban la estilística devocional barroca, todos muy consolidados en el mercado del libro de la época: Luis de Granada, Esteban de Salazar, Pedro de Alcántara, Diego de Estella, Francisco de Osuna, Juan de Ávila, Fray Luis de León, Francisco Ortiz Lucio, Ludovico Blosio...También, en cantidades destacadas, san Juan de la Cruz y santa Teresa, las dos egregias figuras de la mística española del siglo XVI. La canonización de ambos en el XVII favoreció una circulación más fluida de sus obras impresas, hasta entonces de una apreciable difusión manuscrita. La tipografía les devolvió su relevancia cultural y social, su autoridad y magisterio, además de fijar un canon del escrito y anular las copias adulteradas.

Los maestros del Barroco, del mismo modo, están plenamente asentados con unos tratados moralizantes y conducentes a la perfección cristiana muy por encima de la oración interior. No en vano despuntan los jesuitas (con San Ignacio y sus Ejercicios espirituales a la cabeza), los grandes divulgadores del género; entre ellos: los franceses Fleury y Croiset fomentando la devoción del Sagrado Corazón, Luis de la Puente (Directorio espiritual), Señeri (Concordia entre la quietud y la fatiga de la oración). Mucho, Juan Eusebio

18. Quizás el mejor experto en la materia siga siendo Emilio Orozco, Manierismo y Barroco, Madrid, Cátedra, 1981.

19. Algunas de estas cuestiones ya las abordé en "lection espiritual. Lectores y lectura en los libros ascético-espirituales de la Contrarreforma», en Grafías del imaginario..., op. cit. 
Nieremberg, en especial su Diferencia entre lo temporal y eterno y su Aprecio y estima de la divina gracia; seguido de diversas guías para la cimentación de comportamientos y virtudes fomentadas por la jerarquía religiosa, como los Gritos del Purgatorio y Gritos del Infierno de Boneta Laplana, el Luz a los vivos y escarmiento a los muertos del obispo Juan de Palafox, del que también son notorios su Pastor de Nochebuena, Gemidos del corazón y Semana espiritual. Además, la Mistica ciudad de Dios de la madre Ágreda, cientos de Ramilletes de divinas flores, la Reformación cristiana de Francisco de Castro, el Fuero de la conciencia de Valentín de la Madre de Dios y la Introducción a la vida devota de Francisco de Sales.

Las vidas de santos son especialmente significativas. Persisten los dos grandes Flos Sanctorum del Quinientos, el de Alonso de Villegas y el del jesuita Ribadeneyra, quienes nunca dejaron de acaparar ediciones y brindar ganancias; al lado, una larga lista de biografías de personajes distinguidos en piedad y celo religioso, los paradigmas del avatar vital que debe imitar cualquier fiel que quisiere ganar el cielo. Hay muchas hagiografías colectivas (Compendios, Crónicas, Hechos, Elogios, Historias, Martiriologios), con una sección relevante de las dedicadas a órdenes religiosas concretas, objeto de una propaganda competitiva orientada hacia la promoción de cultos e intercesores celestiales. Si bien, de mayor cuantía son las vidas piadosas individuales: san Antonio de Padua, san Francisco, santo Domingo, san Raimundo, san Vicente Ferrer, san Felipe Neri, san Fernando, san Ignacio, santa Catalina de Siena, santa Gertrudis, santa Rosalía; y otras más recientes que desde el siglo XVII vienen ganando cada vez más altos niveles de demanda: santa Teresa, san Juan de la Cruz y, en exaltación de los logros de la evangelización americana, santa Rosa de Lima. Tras ellos una variopinta cohorte de beatos, misioneros y venerables religiosas y religiosos para los que sus autores, mediante la difusión impresa de sus peripecias espirituales, una especie de curricula, aspiran a acelerar sus procesos de canonización: Miguel de Mañara, Gregorio López, Juan de Palafox, el Cardenal Cisneros, Pedro de Alcántara, el padre Ávila, Pedro de Santa María y un dilatado etcétera.

Menos nutrido está ahora el conjunto de tratados monográficos sobre la muerte, pese a ser un tema, recurrente en toda la literatura ascética, fundamental en el Barroco. Los Ars Moriendi, nortes con los que afrontar el tránsito al más allá, están representados por títulos de gran impacto que inculcaron en las masas el objetivo de una buena vida, de acuerdo a la fe profesada, como el mejor arte de bien morir. A diferencia del planteamiento humanista acerca de la contrición final, encumbran la atrición o miedo a la condenación eterna y sus horrores, fórmula en la que se recrean los de Roberto Belarmino, Luis de la Puente, Nieremberg, Luis de Rebolledo y el 
inevitable Alejo Venegas. Finalmente, y a diferencia de los siglos anteriores, son pocos los textos dedicados a Cristo y a la Virgen, incluso desaparecen las tan demandadas vidas de Cristo de Ludolfo de Sajonia y Cristóbal de Fonseca, quizás porque ahora el protagonismo recae en los santos.

Un segmento temático religioso de enorme presencia en los documentos, en función de una altísima demanda clerical y, en especial, de la misional, lo integran la liturgia (cientos de breviarios, diurnos y misales) y la doctrina, capítulos relacionados con la importancia que se le dio a la pastoral y a la predicación durante el Barroco y la Contrarreforma. Notorios son aquí el Catecismo histórico de Fleury, la muy exitosa Luz de verdades católicas y explicación de la doctrina cristiana del también jesuita Juan Martínez de la Parra $^{20}$, la Doctrina de Roberto Belarmino y, como uno de los títulos estrella del XVIII, La familia regulada con doctrina de Antonio Arbiol. Todo ello parapetado con una suculenta cantidad de sermones y repertorios varios de oratoria sagrada. De poesía religiosa no puedo dejar de mencionar el Vergel de flores divinas de Juan López de Úbeda, un título recurrente en las listas de libros manejadas.

De la creación literaria, o poética, en primer lugar he de decir que lo encontrado redunda en el éxito, nada más ver la luz y llegar a las Indias, que a lo largo de todo el periodo colonial alcanzaron ilustres plumas del Siglo de Oro: Mateo Alemán (Guzmán de Alfarache), Cervantes (El Quijote), Lope de Vega y Calderón de la Barca. En cambio, y pese al significativo impacto que tuvo en América, sobre todo en Perú, Góngora casi desaparece de la documentación; pero constan Tirso de Molina y dos autores que murieron de barrocos: Quevedo (con frecuencia advirtiendo su expurgo) y Baltasar Gracián. Tras ellos, con sus novelas, comedias y autos sacramentales, Jerónimo de Salas Barbadillo, Gonzalo de Céspedes y Meneses, Alonso del Castillo Solorzano, Juan Pérez de Montalbán, Zabaleta y María de Zallas. No se ausentan tampoco los dos grandes artífices de la prosa didáctica del XVI: Antonio de Guevara (Epistolas familiares) y Pedro Mexía (Silva de varia lección).

Los autores nacidos en Indias ya van dejándose ver, preferentemente Sor Juana Inés de la Cruz y el Inca Garcilaso. De este último, Carlos III, en 1782, ordenó al virrey de Buenos Aires recoger su obra (la Historia del Perú) con sigilo, si falta hiciere comprándola por terceras personas en secreto y a costa de la Real Hacienda. El objetivo explícito de este decreto,

20. En 1704, el mercader sevillano Francisco Respaldiza registró para Tierra Firme 19 cajones de esta obra. 
siguiendo el ejemplo de Felipe II con libros comprometidos de determinados evangelizadores, fue que esos naturales sin este motivo más de vivificar sus malas costumbres con semejantes documentos. Todavía a finales del siglo XVIII, como en las dos centurias anteriores, se seguía temiendo que la difusión impresa de las costumbres atávicas de los indios suponía un grave obstáculo para su aculturación; tal vez porque la occidentalización americana, después de tanto tiempo, no lograba las metas deseadas. Aunque la justificación que Garcilaso hace de la condición noble de ciertos grupos de incas, competencia exclusiva del Consejo de Indias, y la rebelión de Tupac Amaru también subyacen en la prohibición ${ }^{21}$.

El Setecientos, no obstante, es un tiempo en el que, por coincidir con la decadencia intelectual del Santo Oficio, se relajan la censura e interdicción textual. En general lo literatos hispanos, salvo excepciones, no padecieron un rigor inquisitorial similar al de los dos siglos anteriores; ahora el centro de las atenciones lo acaparan libros, periódicos e ideas del extranjero. Hasta mediados del siglo, conforme al Índice de 1747 (hay otro de 1707), en los discursos jansenistas y regalistas; después, el deísmo, el racionalismo (Pluche, Helvetius, Spinoza, Hobbes, Bayle, Descartes, Bacon...) y la Ilustración (Voltaire, Diderot, Raynal, Condillac, Condorcet, Rousseau, Montesquieu). A raíz de la publicación de Índice de 1790 (con 5.420 prohibiciones), el efecto censor recae en las propuestas revolucionarias procedentes de Francia, o todo pensamiento que pudiere excitar a los pueblos contra los poderes legítimamente establecidos. Tampoco cesó la persecución de obras heréticas o contrarias a la fe, supersticiosas o lascivas, las que atentan contra la moral cristiana y las que circulaban sin nombre de autor, impresor ni lugar y año de edición; o cualquier escrito que pusiera en duda la reputación del prójimo, ante todo autoridades y eclesiásticos ${ }^{22}$.

21. Las dificultades de la circulación de los Comentarios Reales de Garcilaso han sido tratadas con detenimiento por José A Mazzotti, «Garcilaso y los orígenes del garcilasismo: el papel de los Comentarios Real es en el desarrollo del imaginario nacional peruano", Fronteras. Revista del Instituto Colombiano de Cultura Hispánica, n 3, 1998, pp. 13-35; y su Coros mestizos del Inca Garcilaso, Lima, Fondo de Cultura Económica, 1996. También Pedro Guibovich, "Lectura y difusión de la obra del Inca Garcilaso en el virreinato peruano (siglos XVII-XVIII). El caso de los Comentarios Reales», Histórica, n 37, 1990, pp. 103-120.

22. Sigue siendo fundamental Marcelin Defourneaux, Inquisición y censura de libros en la España del siglo XVIII, Madrid, Taurus, 1973; y Ángel Alcalá, Literatura y ciencia ante la Inquisición española, Madrid, Laberinto, 2001. Un gran trabajo es el de Lucienne Domergue, Censure et lumières dans l'Espagne de Charles III, París, CNRS, 1982. Para América tenemos a Abel Ramos, «El Santo Oficio de los calificadores de libros en la Nueva España del siglo XVIII», en Del autor al lector, C. Castańeda coord., México, Porrúa, 2002, pp. 179-200; René Millar Carvacho, «La Inquisición de Lima y la circulación de libros prohibidos (1700- 
Lo más sobresaliente de la muestra obtenida está en el liderazgo de dos obras cumbres de las letras del Siglo de Oro: el Quijote y el Guzmán de Alfarache $^{23}$. Cervantes también se presenta aquí con sus Novelas ejemplares, Comedias y entremeses, Los trabajos de Persiles y Segismunda, La Galatea y el Viaje al Parnaso. Buena prueba del arraigo social del Quijote en Indias fue la presencia de sus personajes centrales en las fiestas populares que allí se celebraban ${ }^{24}$. De otro lado, y como sucedía a partir de mediados del XVII, nada hallamos de los relatos caballerescos y de aventuras fantásticas, bélicas y amorosas, que tanta afición lograron en la sociedad colonial del Quinientos. Parece, por tanto, que algún efecto tuvo el disciplinamiento contrarreformista, pues desde principios del Seiscientos, y aquí, vienen acaparando el mercado las tramas de unos antihéroes tomados de la realidad y que, víctimas de la estupidez, la ignorancia o de sí mismos, al final, y gracias a un rescate providencial, el autor los reintegra en el orden establecido. Todo ello denunciando lacras de su entorno, divirtiendo y moralizando al lector u oyente, aleccionándole y edificándole; de ahí que los escenarios sean sustituidos por la cotidianidad del receptor, donde adquieren autonomía unos personajes en cuyas vivencias el público, próximo y distante a la vez, puede sacar provecho. Así Mateo Alemán, en el prólogo de la primera parte del Guzmán avisa al lector: «En el discurso podrás moralizar según se te ofreciere: larga margen te queda ${ }^{25}$.

En cualquier caso, gobernantes, muchos escritores y moralistas de este tiempo sujetos a la tradición, continuaron una batalla particular, que se remonta al Renacimiento, contra los libros profanos de evasión; convencidos o aparentando convergencia con las voces autorizadas y el prestigio de la norma cultural vigente en esta etapa tardobarroca. Atados seguían a, podríamos decir, un topos retórico que exhibe la condena de todo discurso profano y de evasión, por desacralizante y alejado del entretenimiento cristiano, el único aconsejable y posible. Temían que los jóvenes (las mujeres ante todo, muy aficionadas al género) se dejasen seducir por las conductas deshonestas y lascivas de personajes literarios ficticios, es decir, que sustituyeran la virtud

1820)», Revista de Indias, n 174, 1984, pp. 415-444; y, sobre todo, Pedro Guibovich, Censura, libros e Inquisición en el Perú colonial, 1570-1754, Sevilla, CSIC, Universidad de Sevilla y Diputación de Sevilla, 2003.

23. Como es habitual los registros no suelen especificar si se trata de la primera parte, la segunda o la versión completa de ambos títulos. Tampoco si son las de los oportunistas Avellaneda y Luján.

24. Véase José Montero Reguera, «La recepción del Quijote en Hispanoamérica (siglos XVII al XIX)", Cuadernos Hispanoamericanos, n 500, 1992, pp. 133-140. Y un clásico de Francisco Rodríguez Marín, El Quijote y Don Quijote en América, Madrid, Hernando, 1911. 25. Mateo Alemán, Guzmán de Alfarache, edic. de F. Rico, Barcelona, Planeta, 1983. 
por el pecado. En este clima adverso la novela (romances la llamaban) fue denostada con una riada de reflexiones, radicalizada a finales del siglo objeto de nuestra atención, incluso por los motivos más nimios. Aquellos censores malintencionados, en primer lugar recelaban de la inmoralidad y perversa obscenidad del lenguaje de sus protagonistas; no menos de la exhibición de conductas, eróticas y pasionales, reñidas con el recato y la honestidad ${ }^{26}$. Valga, de la época, la sentenciosa opinión de Manuel José de Ayala cuando comenta el capítulo referido a los libros de las Leyes de Indias:

son perniciosísimas a las buenas costumbres, y a la sociedad, pues se celebran por héroes, los facinerosos; por verdadero valor, lo que es ferocidad delinquente; y por famosas hazañas los más enormes delitos, escandalosas acciones que no tuvieron otro premio que el dogal; y siendo así, se celebran, sin embargo, como gloriosos efectos del valor. ¡O ceguedad del humano entendimiento ${ }^{27}$.

En idéntica dirección va la proclama de un prologuista anónimo de la edición valenciana de 1770 (imprenta de Benito Monfort) del De los nombres de Cristo de Fray Luis de León, en un paratexto introductorio con el título «sobre la necesidad de buenos libros para la instrucción del pueblo», en el que advierte lo siguiente:

En cuanto a los libros de cavallerías, confieso que ya son raros; pero han sucedido en su lugar comedias y novelas más vanas que ellos, más capaces de corromper el ánimo, i lo que es peor, muchas con títulos de morales, de egemplares, i de desengańos: en donde el pueblo miserable beve el veneno creyendo que no le beve; i cuando menos piensa, sin saber cómo ni por dónde, se halla empozoñado i perdido $^{28}$.

No creo que la cita precise de mayores disquisiciones, por sí sola es muy expresiva de cuanto llevamos dicho; aunque no quisiera dejar de mostrar el

26. Al respecto es interesantísimo el ensayo de François Lopez, «Las malas lecturas. Apuntes para una historia de lo novelesco", Bulletin Hispanique, n 2, 1998, pp. 475-514; y Jean-Marc Buigues, "Las lecturas más comunes de los españoles en el siglo XVIII», en el mismo número del Bulletin Hispanique, pp. 515-560. Una visión historiográfica general en Javier Burgos Rincón, «La edición española en el siglo XVIII. Un balance historiográfico», Hispania, $\mathrm{n}^{\circ} 190,1996$, pp. 589-627.

27. Manuel José de Ayala, Notas a la Recopilación de Indias, Madrid, Cultura Hispánica, 1945, p. 73.

28. Se trata de una edición de 1770 realizada en Valencia en la Imprenta de Benito Monfort. 
colofón de la reflexión de este autor anónimo, dice así: «La ceguedad en esto ha llegado a tal grado, que ya muchos juzgan, que las fábulas y teatros (cosas enteramente contrarias al espíritu del cristiano) no sólo son dañosas, sino que pueden corregir y formar las costumbres.»

Otra de las cotas de embarque más elevadas la alcanza el teatro, baste mencionar el envío a Tierra Firme (el 16 de mayo de 1713) que un tal Alonso Rubio Rivas remite a Juan García Noriega con 1.500 cartillas, 13 docenas de catones, 44 docenas de doctrinas y 504 comedias de diferentes historias $^{29}$. Un surtido, propio de misioneros, que ya nos está anunciando la importancia del género en la evangelización y, en general, la popularidad de las representaciones teatrales en la sociedad colonial. En nuestra muestra van exquisitamente representadas por Cervantes, Tirso de Molina, Calderón de la Barca y, ante todo, Lope de Vega, quien en función de los registros de los siglos XVII y XVIII, tal vez fuera el autor que más veces cruzó el Atlántico $^{30}$. Aparte de cientos de ejemplares de sus Comedias famosas, son muy significativas La Arcadia, La hermosura de Angélica, San Isidro y, mucho, El peregrino en su patria. El protagonismo, obvio es, lo acapara la comedia, ya rehabilitada tras las diatribas barrocas; mas en el XVIII tampoco se libró de las licencias ni de las censuras civiles y eclesiásticas. No obstante los ilustrados defendieron los provechos didácticos del teatro, pero sin excluir la vigilancia de sus argumentos y de las puestas en escena. Jovellanos, por ejemplo, exalta sus cualidades cuando se ponía al servicio del poder y de tramas didácticas, ajenas a fantasías e indecencias, como las gloriosas hazañas de la historia de España.

Campomanes, con su entusiasta y paternalista paradigma de educación popular, lo creía tan necesario en la sociedad como el abasto de alimentos, eso sí, contando con los gustos del vulgo y, siempre, bajo la supervisión de la autoridad con objeto de garantizar el respeto a los cánones políticos, religiosos, sociales y familiares. Otros anclados en la tradición barroca -tal es el caso del prologuista anónimo arriba mencionado- vieron en las tramoyas un remedo de los libros de caballerías. La Inquisición, por su parte, se limitó a fiscalizar la temática sagrada. Como producto impreso fue asequible incluso a los escalafones inferiores, pues circulaba en formatos muy baratos (pliegos,

29. Este surtido ya lo examinó José Torre Revello, El libro, la imprenta y el periodismo en América durante la dominación española, Buenos Aires, Instituto de Investigaciones Históricas, 1940.

30. A estas conclusiones se puede llegar con las investigaciones, ya citadas, de P. Rueda y Carlos A. González. De Leonard, Irving A.: «Notes on Lope de Vega’s Works in the Spanish Indies», Hispanic Review, n 6, 1938, p. 282. 
folletos en rama) y efímeros, por ello ha resistido mal el paso del tiempo. Muy superior, en cambio, fue el éxito de sus representaciones escenográficas, destino que daba lugar a importantes variaciones del escrito original, a diferentes versiones dependiendo de que su escenificación fuera en corrales de comedias o en las cortes reales y señoriales ${ }^{31}$.

La escasez de medios de información social hizo que simultáneamente fuera un gran núcleo de sociabilidad, en el que circulaban noticias del mundo, aunque acomodadas a los fines de la propaganda gubernamental y religiosa. A este cometido contribuyeron sus recursos efectistas plásticos y visuales que, ya sea en el caso de Lope de Vega o en el de los jesuitas en sus colegios y misiones, despliegan una exaltación del sistema monárquicoseñorial, del orden y de las conductas ideales del súbdito católico ${ }^{32}$. Su capacidad de penetración y de provocar emociones en las masas iletradas (asombro, miedo, piedad, llanto, risa) explica el auge de la comedia, pero también el recelo de las autoridades y los censores. No es de extrañar, pues, que la jerarquía eclesiástica y los moralistas siempre la tuvieran en baja estima y en el punto de mira, por ser un género, según ellos, profano y lleno de deshonestas pasiones sensuales. Palafox, enemigo de los jesuitas, la aborrece y la tilda de peste de la república, cátedra de pecados, tribunal del demonio que conduce a la emulación de vicios inadmisibles y nocivos. Pero, peor aún veía su circulación impresa, porque, como puntualiza, la pueden leer por los ausentes. Sea como fuere el teatro fascinó a la América colonial, donde acaparó el gusto de todos los estratos sociales, a los que, con motivos del folklore, cuentos y romances, a la vez de entretener y divertir, aleccionaba ${ }^{33}$.

\section{ECOS DE LA ILUSTRACIÓN}

En la segunda mitad del siglo XVIII es cuando, de manera desigual, irrumpen en las Indias las ideas ilustradas, un tiempo en el que la imprenta conocería un importante ensanche de su geografía en el Nuevo Mundo ${ }^{34}$.

31. Roger Chartier, «Prácticas del teatro. Escribir, ver y leer la comedia en el Siglo de Oro», en su Escribir las prácticas: discurso, práctica, representación, Valencia, Universidad de Valencia, 1998, pp. 87-98.

32. José A De Maravall, Teatro y literatura en la sociedad barroca, Barcelona, Crítica, 1990.

33. Sobre estas cuestiones Adam Versényi: El teatro en América Latina, Cambridge, Cambridge, University Press, 1996. Unas interesantes notas también introduce Magdalena Chocano Mena, La América colonial (1492-1763). Cultura y vida cotidiana, Madrid, Síntesis, 2000.

34. Ma Ángeles De Eugenio Martínez, La Ilustración en América (siglo XVIII), Madrid, 
Localidades como La Habana, Santo Domingo, Bogotá y Buenos Aires contemplaron y experimentaron la llegada de la tipografía ${ }^{35}$. Estas primicias surtieron algún efecto en la circulación del impreso en el mundo atlántico, visible en el perfil de los libros enviados desde España, sobre todo a partir de la expulsión de los jesuitas (1767). La exclusión de la Compañía de Jesús quizás pueda explicar la reducción, leve, de los textos religiosos en el panorama americano, disminución que, a la vez, coincide con una mayor fluidez de corrientes del pensamiento sacro entonces novedosas y contrarias a los presupuestos ideológicos de la orden ignaciana, como el jansenismo y el quietismo ${ }^{36}$. Simultáneamente se produce un cierto retroceso de la escolástica y del férreo tomismo defendido por ellos y unos dominicos anclados en sus cátedras universitarias; también, un discreto auge de los "novatores», del círculo valenciano, o defensores de los nuevos y revolucionarios métodos científicos en boga (Tosca, Piquer, Climent, Beltrán, Berni), el germen hispánico de la compleja renovación de unos planes de estudios superiores que Carlos III, a golpe de decreto (1770), quiso dotar de buenos libros ${ }^{37}$. Feijoo, en esta coyuntura, fue figura de primer orden en los repertorios tipográficos de las Indias, cuyas obras, además de lamentar el retraso intelectual de España, reivindican la síntesis entre ciencia y religión. Otros libros traslucen el impacto de una teoría política alternativa y comprometida con el galicanismo y un racionalismo crítico con el absolutismo, explícita en las difundidísimas Las aventuras de Telémaco de Fénelon, texto que enuncia la primacía de la ley sobre la voluntad real. Ya en el último tercio del siglo las bibliotecas particulares nos dejan ver (fruto del contrabando y de las fallas del sistema de control de la Carrera de Indias) la sigilosa irrupción de los ilustrados franceses, deístas, ateos y racionalistas; tan polémicos y prohibidos como Locke, Montesquieu, Voltaire Rousseau, Condillac, Condorcet, Pluche, Helvetius, Spinoza y Hobbes, Bayle, Raynal, Diderot, D’Alembert, Arnauld, Mably y Volney ${ }^{38}$.

Anaya, 1988. Más reciente el de Diana Soto, Miguel A Puig-Samper y Luis C. Arboleda, $L a$ Ilustración en América colonial: bibliografía crítica, Aranjuez, Doce Calles, 1995.

35. Sobrada información en Stella M. Fernández, «El libro en Hispanoamérica», en Historia ilustrada del libro español. De los incunables al siglo XVIII, H. Escolar dir., Madrid, Pirámide, 1994, pp. 447-498.

36. Muy buen estudio es el que desarrolla Enrique Villalba Pérez, Consecuencias educativas de la expulsión de los jesuitas de América, Madrid, Dykinson, 2003.

37. Esta tendencia también la aprecia Carmen Ma Panera Rico en su investigación: Los libros de la Ilustración. Iglesia, ideología y mentalidad en Venezuela (1759-1789), tesis doctoral inédita, Sevilla, Universidad de Sevilla, 1998.

38. Un buen caudal de información al respecto ofrece el libro colectivo Recepción y difusión de textos ilustrados. Intercambio cientifico entre Europa y América en la Ilustración, Madrid, 
$\mathrm{Si}$ atendemos a los libros que se enviaban a Brasil desde Lisboa, entre 1769 y 1807, la literatura más representativa (el $55 \%$ corresponde a escritos de ficción) abarca un conjunto de libros en el que destacan, en primer lugar, Las aventuras de Telémaco de Fénelon, uno, como vimos, de los best seller del tráfico ultramarino. Le siguen los Night Thoughs on Life Death and Inmortality de Edward Young, los Selecta Latini Sermonis de Pierre Chompré, la picaresca Histoire de Gil Blas de Santillane de Alain René Lesage, Le voyageur François ou la connoissance de l'ancien et du nouveau monde de Joseph Laporte, las Meditations and Contemplations de James Hervey o The Paradise Lost de John Milton. Junto a ellos otros que ya venían despuntando desde mucho tiempo atrás: Don Quijote, la Historia del Emperador Carlo Magno y los doce pares de Francia, las Obras de Camoens, las Rimas de Manuel María Barbosa, las Rimas de Joâo Xavier de Mattos y las Fábulas de Esopo ${ }^{39}$.

En esta etapa finisecular el empeño de la Inquisición, en extremo temerosa de las ideas ilustradas (su espada de Damocles dice Domergue), fue acabar con el incontrolable tráfico de libros prohibidos, en el que influyó notoriamente la abultada colonia de mercaderes franceses afincada en Cádiz, y las numerosas licencias para leer textos censurados que el Santo Oficio concedía, preferentemente a religiosos, pero también a muchos laicos. El colmo de tanto despropósito fue la Real Instrucción de 13 de noviembre de 1782, que permitía a todos los extranjeros transeúntes en los dominios de la Corona el uso privado de sus libros, aunque estuviesen en el Índice. El jurista Ayala, a mediados de la centuria, ya advertía la relajación e ineficacia del control inquisitorial en la Carrera de Indias, acusando a sus comisarios y a los oficiales reales de desidia en el examen de los registros y de la carga de los navíos; antes que nada del «superficial reconocimiento de personas que no lo entienden de que, si no han resultado, pueden resultar gravísimos daños» ${ }^{40}$. Y, como denunciara Veitia Linaje a finales del XVII, apostilla que

Doce Calles, 2003; y Mónica Quijada y Jesús Bustamante (eds.), Elites intelectuales y modelos colectivos. Mundo Ibérico (siglos XVI-XIX), Madrid, CSIC, 2003. De Rosario Márquez Macías, El trasvase cultural a América. Las bibliotecas privadas de los emigrantes españoles en el siglo XVIII, Huelva, Aconcagua Libros, 2002.

39. Marcia Abreu, op. cit. En otra línea Rubens Borba de Moraes, «Livros e Bibliotecas no Brasil colonial (1500-1808)», Revista Interamericana de Bibliografía, n 3, 1973, pp. 227241.

40. Manuel J. Ayala, op. cit., p. 92. 
no es menester mucha reflexión para inferirlos; y las precauciones que debían tomarse, pues es inútil la presentación de la lista, porque han solido rotularse como obras de Santa Teresa o Fr. Luis de Granada las de Pufendorf, y otras peores, poniendo en las cubiertas de aquellos libros los títulos que digo ${ }^{41}$.

A ello se debe su insistencia en el reclamo de una mayor eficacia en las fuentes de información de las entidades implicadas en la vigilancia de las aduanas, especialmente en la fiscalización de los libros internacionales y de los que, pese a los decretos de 1739, 1741, 1751 y 1758, se imprimían en Indias sin licencia del Consejo.

Remedio urgente requerían las corrupciones detectadas en el puerto de Cádiz, donde los oficiales de la Contratación eran los primeros que obstaculizaban el trabajo de los inquisidores permitiendo, en connivencia con los libreros, el embarque de impresos foráneos sin licencia. Estas componendas se descubrieron en la visita general de las librerías gaditanas realizada en 1772, inspección que destapó centenares de impresos franceses sin calificar. En esta disyuntiva del tráfico ilegal influyó decisivamente la inversión de las alianzas interestatales de Carlos III, un nuevo esquema diplomático que relegó a Inglaterra en favor de Francia y, en última instancia, de sus mercaderes y libreros. Al final se impusieron los impedimentos de las pretensiones autoritarias y centralistas de un gobierno continuamente doblegado por las distancias, la lentitud de los transportes, una rudimentaria administración, los intereses institucionales y de las autoridades locales y la ineficacia de los medios de difusión y cumplimiento de las leyes. Al mismo tiempo el de unos mercaderes que, en consonancia con la Inquisición, velaban por su monopolio frente a los libreros del resto de Europa. El Santo Oficio, pese a la ineficacia de sus actuaciones, en todo momento, con sus efectistas visitas, edictos, encausamientos y proclamas se hacía presente e interiorizaba sus recelos en las conciencias de la población; de ahí que debamos relativizar nuestros juicios negativos sobre sus resultados y consecuencias. 
